\title{
The expansion of the global gag rule under the Trump administration
}

\author{
Sarah Rominski ${ }^{1, *}$ | Scott Greer ${ }^{2}$ \\ ${ }^{1}$ Department of Obstetrics and Gynecology, University of Michigan Medical School, Ann Arbor, MI, USA \\ ${ }^{2}$ Department of Health Management and Policy, University of Michigan School of Public Health, Ann Arbor, MI, USA \\ ${ }^{*}$ Correspondence \\ Sarah Rominski, Department of Obstetrics and Gynecology, University of Michigan Medical School, Ann Arbor, MI, USA. \\ Email: sarahrom@med.umich.edu
}

Surrounded by a group of older, white men, President Donald Trump, on January 23, 2012, signed his executive order reinstating the Reagan-era Mexico City policy, or "global gag rule" as it is also known. ${ }^{1}$ This policy prohibits American-funded non-governmental organizations (NGOs) in other countries from discussing abortion or providing referrals for abortion. To be precise: not only is it illegal to use US aid funds for abortion referral and information, it is, under the gag order, impossible for an organization that receives US aid to use funds from other donors for these activities. While the Trump administration's decision to reinstate this rule was disheartening to many working in the field of global reproductive health, it was not surprising. This policy has been implemented by every Republican administration since Reagan, and reversed by every Democratic administration.

However, it soon became clear that this time it was different; the Trump administration had not simply reinstated the Mexico City policy, but had greatly expanded it. The gag rule historically applied to the approximately US\$600 million per year that the USA spends in bilateral family planning assistance. ${ }^{2}$ The Trump administration order restricting the mention of abortion, however, also applies to all "global health assistance furnished by all departments or agencies." The scope of this order puts an estimated $\$ 9.5$ billion in foreign aid under this new gag order. While the George W. Bush administration specifically exempted agencies that were funded by the President's Emergency Plan for AIDS Relief (PEPFAR; the multi-billion dollar investment in African health systems to address the HIV/AIDS crisis) from the gag rule, ${ }^{4}$ there are no exemptions in the Trump administration version.

The gag rule makes work very difficult for the recipients of US aid: they would have to run almost completely segregated programs to satisfy US conditions. Its extent also means that organizations unaccustomed to working around the gag rule-e.g. those receiving assistance from the Centers for Disease Control and Prevention (CDC) or the Food and Drug Administration-will have to determine if they can operate under these terms and, if they can, reorganize to do so. So far there has been no guidance from the Trump administration on how to implement this new version of the policy. Some NGOs will not. The Planned Parenthood International Federation and Marie Stopes International both announced that they refuse to comply with US terms. The end of US support to those two organizations alone will be a major blow to global family planning and reproductive rights.

The impacts of the new-model gag rule are widespread and will be detrimental to millions of the world's most vulnerable women. While the Mexico City Policy is lauded by anti-abortion activists in the USA as a way to limit activities that might enable or promote abortion (as the 1974 Helms amendment already precludes any agency from using US taxpayer money to pay for abortions), there is ample evidence that abortions increase when this ban is in place due to reduced access to contraceptive services. ${ }^{5,6}$ According to this new order, it seems the USA will have to certify that agencies receiving US funds have never referred a patient for an abortion or discussed abortion with their patients. International NGOs will be in a position to choose between taking massive funding cuts if they refuse to be muzzled by this order, or offering care to women that neglects an oftentimes medically indicated procedure. While some clinics in low-income settings provide only reproductive health care, many offer holistic services to their clients, and being able to discuss abortion as an option is providing the best care for patients. There is no good way to operate global health services without integrating abortion advice and referrals, if not actual provision of services.

Since the ban was announced in January, the international community has responded. Countries such as Norway, Belgium, and the Netherlands have pledged $\$ 10$ million each to cover the shortfall created by this policy, as part of the initiative named "She Decides." A consortium of other countries may join these activities. Sadly, these generous pledges will not come close to the estimated $\$ 9$ billion that will be lost to the international aid community. Furthermore, the history of foreign aid pledges of any kind is a dispiriting one: actual sums of aid tend to be far 
less than the amounts pledged. As a result, there will be considerable scope for political pressure on governments to make and fulfill their pledges. Citizens of countries outside the USA have an opportunity here, as do private donors who can also compensate for some of the loss. Within the USA, there is still scope for agencies to write guidelines that minimize the impact of the gag rule on, for example, communicable disease control supported by CDC. Otherwise, though, the gag rule will remain policy until at least Inauguration Day in 2021.

\section{AUTHOR CONTRIBUTIONS}

Both authors wrote and developed the paper.

\section{CONFLICTS OF INTEREST}

The authors have no conflicts of interest.

\section{REFERENCES}

1. Barot S, Cohen SA. The global gag rule and fights over funding UNFPA: the issues that won't go away. https://www.guttmacher.org/ gpr/2015/06/global-gag-rule-and-fights-over-funding-unfpa-issueswont-go-away. Published June 3, 2015. Accessed March 7, 2017.

2. The Henry J. Kaiser Family Foundation. US funding for international family planning and reproductive health. http://kff.org/ global-health-policy/issue-brief/u-s-funding-for-internationalfamily-planning-reproductive-health/view/. Published April 25, 2016. Accessed March 7, 2017.

3. The White House. Presidential Memorandum Regarding the Mexico City Policy. https://www.whitehouse.gov/the-press-office/2017/01/ 23/presidential-memorandum-regarding-mexico-city-policy. Published January 23, 2017. Accessed March 7, 2017.

4. Dietrich JW. The politics of PEPFAR: The President's emergency plan for AIDS relief. Ethics Int Aff. 2007;21:277-292.

5. Bendavid E, Avila P, Miller G. United States aid policy and induced abortion in sub-Saharan Africa. Bull World Health Organ. 2011;89:873-880C.

6. Jones KM. Contraceptive supply and fertility outcomes: Evidence from Ghana. Econ Dev Cult Change. 2015;64:31-69. 